\title{
O Supremo Tribunal Federal (STF) como locus da razão pública
}

\author{
The Supreme Court (STF) as a locus of public reason
}

Robison Tramontina

Doutor em Filosofia pela Pontifícia Universidade Católica do Rio Grande do Sul (PUC-RS). Professor do Programa de Mestrado em Direitos Fundamentais da Universidade do Oeste de Santa Catarina (UNOESC). E-mail: robison.tramontina@unoes.edu.br

Anny Marie Santos Parreira

Graduada em Direito pela Faculdades Cathedral/RR; Especialista em Direito Público pela Fundação Escola do Ministério Público/RS e Mestranda em Direitos Fundamentais - Universidade do Oeste de Santa Catarina (UNOESC). E-mail: annymarieps@gmail.com

RECEBIDO EM: 17.06.2014

APROVADO EM: 02.08.2014

\section{RESUMo}

Trata-se de investigar em que medida pode o SUPREMO TRIBUNAL FEDERAL (STF) o ser considerado o lugar apropriado e legítimo para resolver questões políticas fundamentais. Defende-se a tese, a partir da teoria rawlsiana, de que o uso da razão pública como procedimento de justificação e de aplicação dos princípios da justiça, por suas características, oferece uma plataforma satisfatória para a resolução dos desafios inerentes a sociedades complexas e que o Supremo Tribunal Federal (STF) exprime ou deveria exprimir aquela. Para dar conta do problema proposto adotar-se-á seguinte estratégia argumentativa: (i) um retrato geral de algumas das ideias apresentadas em $O$ Liberalismo Político $(L P)$, para na sequência, depois de reproduzida a estrutura da razão pública rawlsiana, analisar o papel de tal ideia no Supremo Tribunal Federal. O Tema é juridicamente relevante, pois oferece um critério de reflexão e aferição da legitimidade de decisões políticas em sociedades democráticas e fornece diretrizes para a identificação, racional, das ações políticas que defendem ou violam os princípios de justiça de um Estado democrático de direito.

Palavras-chave: Teoria da justiça. Razão pública. Liberalismo Político. 


\begin{abstract}
It is investigated to what extent can the FEDERAL SUPREME COURT (STF) to be considered proper and legitimate place to address key policy issues. Defends the thesis, from the Rawlsian theory, that the use of public reason and justification and application of the principles of justice, by its characteristics procedure provides a satisfactory platform for addressing the challenges inherent in complex societies and the Federal Supreme Court (STF) expresses or should express that. To account for the proposed problem will take up next-argumentative strategy: (i) a general picture of some of the ideas presented in Political Liberalism (LP), for following, after playing the structure of Rawlsian public reason, analyze role of this idea in the Supreme Court. The Theme is legally relevant because it provides a criterion for reflection and assessment of the legitimacy of political decisions in democratic societies and provides guidelines for the identification, rational, policy actions that defend or violate the principles of justice in Rule of Law.
\end{abstract}

Keywords: Theory of Justice. Public reason. Political liberalism.

SumÁrio: Considerações iniciais. 1. O liberalismo político e suas principais categorias. 1.1. A concepção política de justiça. 1.2. A concepção política de pessoa. 1.3. Consenso sobreposto. 1.4. A ideia de razão pública. 2. O papel da razão pública no Supremo Tribunal Federal. Conclusão. Referências.

\title{
CONSIDERAÇÕES INICIAIS
}

Para Rawls ${ }^{190}$ a cultura política de uma sociedade democrática tem como uma de suas principais características o pluralismo razoável. O pluralismo é uma marca das sociedades modernas democráticas. Essas comportam uma diversidade de doutrinas religiosas, filosóficas e morais abrangentes e razoáveis. Uma sociedade é plural se admite e possibilita que se desenvolvam diversas doutrinas razoáveis. Pode-se dizer que o pluralismo é condição necessária desses tipos de sociedades.

Sendo assim, em regimes democraticamente constitucionais, a coexistência plúrima de diversas concepções filosóficas, religiosas e morais abrangentes e razoáveis é o resultado natural da existência de instituições livres. Esse é o aspecto positivo do pluralismo. Contudo, ele obsta uma base de acordo comum referente a

${ }^{190}$ RAWLS, John. Political Liberalism. New York: Columbia University Press, 1996. 
temas públicos, políticos e jurídicos ${ }^{191}$. Aqui a falta de consenso pode ser considerada a consequência negativa do pluralismo.

Sendo assim, uma vez que a vida social compartilhada demanda certos acordos. Pergunta-se: i) como tornar possível um possível um acordo ou aproximar de entendimento mútuo acerca das questões públicas essenciais? ii) Como assegurar que os direitos, as liberdades e garantias dos indivíduos e grupos que compõem o corpo social sejam respeitados e efetivados? iii) a quem compete garantir o acordo e as proteções políticas-jurídicas necessárias para o consenso ocorrerá? iv) que tipo de consenso é possível?

Dado o cenário acima destacado, trata-se de, a partir da teoria rawlsiana, defender a tese de que o uso da razão pública como procedimento de justificação e de aplicação dos princípios da justiça, por suas características, oferece uma plataforma satisfatória para a resolução dos desafios inerentes a sociedades complexas e que o Supremo Tribunal Federal (STF) exprime ou deveria exprimir aquela.

Nesses termos, pretende-se abordar no presente artigo a tese rawlsiana que sustenta que as Cortes Constitucionais devem/podem ser o locus para a manifestação da razão pública, logo, elas seriam/são os locais por excelência da deliberação racional e das melhores soluções para as questões essenciais do âmbito político.

Da temática proposta extrai-se o seguinte problema: Em que medida pode o STF o ser considerado o lugar apropriado e legítimo para resolver questões políticas fundamentais ${ }^{192}$ ?

Para dar conta do problema proposto adotar-se-á seguinte estratégia argumentativa: (i) um retrato geral de algumas das ideias apresentadas em $O$ Liberalismo Político $^{193}(L P)$, para na sequência, depois de reproduzida a estrutura da razão pública rawlsiana, analisar o papel de tal ideia no Supremo Tribunal Federal.

A escolha do tema exposto justifica-se, fundamentalmente, pelas seguintes razões: a) é juridicamente relevante, pois oferece um critério de reflexão e aferição da legitimidade de decisões políticas em sociedades democráticas ${ }^{194} \mathrm{e}$; b) fornece diretrizes para a identificação, racional, das ações políticas que defendem ou violam os princípios de justiça de um Estado democrático de direito.

Por trata-se de estudo em estágio inicial, adota-se, como metodologia de

191 “[...]os cidadãos das sociedades democráticas modernas defrontam-se permanentemente com o problema de encontrar uma base comum para a resolução de seus conflitos e para a formação de acordos políticos sobre os fins, valores e normas que devem reger as práticas e instituições da vida em comum". WERLE, Denilson. Justiça e Democracia: Ensaios sobre John Rawls e Jürgen Habermas. São Paulo: Singular; Esfera Pública, 2008. p.26.

192 As questões políticas, para Rawls, dizem respeito à: (i) questões constitucionais essenciais: princípios fundamentais que especificam a estrutura geral do Estado e do processo político e; direitos e liberdades fundamentais iguais. (ii) questões de justiça básica. RAWLS, John. A Theory of Justice. Cambrigde: Harvard University Press. 1999.

${ }^{193}$ RAWLS, John. Political Liberalism. New York: Columbia University Press, 1996.

${ }^{194}$ Sociedade que se estabelece como um sistema equitativo de cooperação 
abordagem e apresentação, a proposta estruturalista. ${ }^{195}$ Sendo assim, é uma leitura interna, não comparativa e não problematizadora da teoria rawlsiana.

\section{O LibERALISMO POLÍTICO E SUAS PRINCIPAIS CATEGORIAS}

O Liberalismo Político (LP) é um conjunto oito de conferências produzidas por Rawls, nos anos 80 com o propósito de propor uma alternativa a "um grave problema interno" da Justiça como Equidade, a saber: a ideia pouco realista de sociedade bem ordenada. De acordo com ele, isso afeta a descrição da estabilidade apresentada em Uma Teoria da Justiça (TJ), porque a Justiça como Equidade fora concebida como uma doutrina filosófica abrangente, incompatível com o pluralismo razoável das sociedades democráticas modernas. Com as alterações em algumas noções e a introdução de novas ideias, Rawls pretendia eliminar as ambiguidades presentes em TJ e apresentar uma concepção política de justiça. Assim, o objetivo dele, em LP, é “descobrir em que condições é possível haver uma base de justificação pública razoável no tocante a questões políticas fundamentais". ${ }^{196}$

Alguns estudiosos ${ }^{197}$ da obra de John Rawls chamam a atenção para o denominado giro político do LP, uma vez que nessa obra, em detrimento à pretensões universalistas e conteúdos metafísicos apresentados em TJ Rawls imprime à sua concepção de justiça um filtro político.

O LP abre com duas questões referentes à justiça política numa sociedade democrática. A primeira é uma questão de justiça distributiva. Aqui estão em discussão os termos equitativos da cooperação social entre cidadãos considerados livres e iguais: qual a concepção de justiça capaz de fundar adequadamente referidos termos? A segunda remete ao problema da tolerância: quais são os fundamentos da tolerância? As sociedades democráticas caracterizam-se pelo pluralismo razoável, ou seja, os cidadãos livres e iguais concebem diversas, e em algumas situações, até irreconciliáveis concepções do bem. ${ }^{198}$ Como tornar possível sua convivência? Essa diversidade é um traço que indica a própria dinâmica e a natureza desse modelo social.

Essas duas questões combinadas remetem a uma terceira, a da estabilidade. Esta se expressa nos seguintes termos: "como é possível existir, ao longo do tempo, uma sociedade justa e estável de cidadãos livres e iguais, mas que permanecem pro-

\footnotetext{
${ }^{195}$ Essa opção é apenas metodológica. A leitura estrutural é adequada para pesquisas em fases inicial. Ela permite identificar as partes, suas inter-relações e sua posição na totalidade.

${ }^{196}$ RAWLS, 1996. Op. cit., p.xxi.

${ }^{197}$ Por exemplo: GAUS, Gerald. The turn to Political Liberalism. Disponível em: http:// www.gaus.biz/PoliticalLiberalism.pdf . Acesso: 21/08/14. WEITHMAN, Paul. Why Political Liberalism. On John Rawls's Political Turn. New York: Oxford University Press, 2011.

198 WERLE, Denilson Luis. Justiça e Democracia: Ensaios sobre John Rawls e Jürgen Habermas. São Paulo: Singular; Esfera Pública, 2008.
} 
fundamente divididos por doutrinas religiosas, filosóficas e morais razoáveis"199. Ela constitui a questão fundamental de LP. Combinando as questões tem-se o problema do Liberalismo. Esse consiste em "formular uma concepção de justiça política para um regime democrático constitucional que a pluralidade de doutrinas razoáveis pode [...] pode endossar". ${ }^{200}$ Em outros termos, pode-se dizer que Rawls pretende responder basicamente, duas perguntas, a saber: a) qual concepção de justiça é mais adequada para especificar, em uma sociedade democraticamente constitucional, e b) quais são as bases da tolerância?

A proposta rawlsiana, considerada em seu conjunto, pretende apresentar uma concepção de justiça que possa fundar uma sociedade justa e estável, apesar e a partir do pluralismo razoável. Contudo, em LP, o foco das reflexões desloca-se para a ideia de estabilidade, relegando menos importância à questão da justiça. Além de ter ocorrido uma alteração na preocupação central das reflexões, embora elas possam ser pensadas de forma contínua, algumas mudanças na justificação de argumentos apresentados em TJ, novos conceitos, alguns temas e discussões foram excluídos. O primeiro pode ser visto, por exemplo, pela introdução de novos argumentos a favor dos princípios de justiça. O segundo pelas novas ideias que são desenvolvidas em LP, a saber: concepção política de justiça, consenso sobreposto, concepção política de pessoa, pluralismo razoável e razão pública.

Na sequência destacar-se-á e analisar-se-ão alguns destes conceitos.

\subsection{A CONCEPÇÃo POLÍtiCA DE JUSTIÇA}

A preocupação fundamental do Liberalismo é formular uma concepção política de justiça. Uma concepção política de justiça é entendida como uma concepção moral, que se aplica à estrutura básica da sociedade (instituições políticas, sociais e econômicas) constituída como uma visão autossustentada que tem seu conteúdo expresso, através de algumas ideias vistas como implícitas na cultura política pública de uma sociedade democrática. ${ }^{201}$

Uma concepção política de justiça é moral, na medida em que seu conteúdo é determinado por normas que articulam valores políticos. Por exprimir valores políticos, apresenta-se como uma concepção moral ${ }^{202}$. Foi concebida para ser aplicada apenas à estrutura básica da sociedade. Por conseguinte, sua extensão limita-se ao âmbito político.

Para Rawls uma concepção política de justiça tem três características dominantes: a) ela especifica determinados direitos, liberdades e oportunidades (principalmente as que dizem respeito ao bem geral e a valores perfeccionistas); b) ela

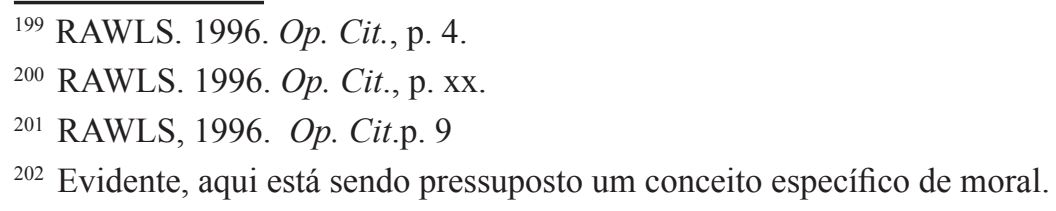


prioriza tais direitos e, c) oferece medidas que assegurem a todos os cidadãos os meios necessários para a prática efetiva desse conteúdo.

Sendo assim, a concepção de justiça política aparece como uma visão autossustentada por não decorrer ou não precisar pressupor ou fazer referência à outra concepção moral geral ou abrangente. Uma concepção moral é geral quando se aplica a todos os objetos de forma universal. É abrangente, por tratar de diversos aspectos da vida humana, indo desde o que é valioso para a vida humana até a indicação de quais condutas são adequadas. Distintamente, uma concepção política de justiça aplica-se apenas à estrutura básica da sociedade e não se vincula a qualquer outra doutrina:

[...] a concepção política é um módulo, uma parte constitutiva essencial que se encaixa em várias outras doutrinas abrangentes razoáveis subsistentes na sociedade regulada por ela, podendo conquistar o apoio daquelas doutrinas [...]Uma concepção política tenta elaborar uma concepção razoável somente para a estrutura básica e não envolve, na medida do possível, nenhum compromisso mais amplo com qualquer outra doutrina ${ }^{203}$.

A partir do exposto constata-se que Rawls propõe uma concepção de justiça estritamente política sem compromissos ontológicos, lógicos e morais com qualquer outra concepção e capaz de dar conta da pluralidade moral, filosófica e religiosa das sociedades democráticas modernas. Um ponto controverso é a questão da possibilidade de se elaborar uma concepção política moral e filosoficamente neutra. Temse a impressão que toda concepção política mesmo não exprimindo certas crenças morais ou filosóficas, necessita em geral, pressupô-las.

Na proposta de Rawls, a concepção política de justiça tem como conteúdo ideias que estão implícitas na cultura política pública ${ }^{204}$ de uma sociedade democrática. Esta apresenta uma cultura política e uma social. A cultura política é constituída pelas instituições políticas de um regime constitucional e suas interpretações, bem como por textos e documentos históricos. A cultura social (cultura de fundo) é a cultura da vida cotidiana, das igrejas, universidades e sindicatos entre outros. O que diferencia uma da outra é o fato das ideias e dos princípios da cultura política serem acessíveis e compartilhados pelos cidadãos. Por exemplo: posso não acessar e compartilhar ideias e princípios defendidos por uma determinada igreja ou sindicato, mas não posso dizer o mesmo em relação a Constituição do meu país.

Importa destacar que Rawls não extrai ou deduz o conteúdo de sua concep-

\footnotetext{
${ }^{203}$ RAWLS, 1996. Op. Cit., p.12.

${ }^{204}$ A cultura pública de uma sociedade democrática caracteriza-se por três fatos gerais: pluralismo razoável resultado de exercício da razão prática livre, a impossibilidade de se ter uma única doutrina abrangente sem recorrer ao uso da coerção estatal e regime democrático deve ser apoiado livre e voluntariamente pelos cidadãos politicamente ativos.
} 
ção de justiça de qualquer procedimento lógico ou pressuposição metafísica. Ela a identifica no substrato de uma tradição política (democrática) gestada e constituída historicamente nas sociedades democráticas.

Para finalizar, de acordo com Rawls, apenas uma concepção política de justiça é capaz de conquistar o apoio de um consenso sobreposto ${ }^{205}$, imprescindível para a unidade social e a estabilidade. Nesse sentido, é falha toda concepção de justiça que não recebe apoio de cidadãos razoáveis que professam doutrinas abrangentes razoáveis.

\subsection{A CONCEPÇão POLÍtiCA DE PESSOA}

Rawls $^{206}$ extrai sua concepção de pessoa ${ }^{207}$ da cultura política pública das sociedades democráticas. Na tradição democrática presente nestas destaca-se a ideia de que os cidadãos são pessoas livre e iguais. Mas o que significa dizer que os cidadãos são pessoas livres e iguais?

O conceito de pessoa desde a sua concepção no mundo antigo está associada a ideia de representação. Ser pessoa é representar um papel, seja no teatro ou na vida social. Na esfera social ou política alguém é pessoa quando toma parte ou desempenha um papel próprio desses âmbitos. Em termos políticos, quando alguém é uma pessoa, ele é um cidadão.

As pessoas (cidadãos) são livres porque são portadores de duas faculdades morais (a capacidade de ter senso de justiça ${ }^{208}$ e ter uma concepção de bem ${ }^{209}$ ) e das faculdades da razão (de julgamento, pensamentos). São iguais porque a posse dessas faculdades as tornam membros cooperativos da sociedade.

Para entender melhor o que Rawls quer dizer com uma concepção política de pessoa é necessário destacar um outro argumento. De acordo com esse, os cidadãos são livres em três aspectos, a saber: a) por possuírem a faculdade moral de ter uma concepção do bem; b) por serem fontes autenticadoras de reivindicações e c) por serem capazes de assumirem responsabilidades por seus objetivos. Abaixo uma breve explicação sobre cada um desses tópicos:

\footnotetext{
${ }^{205}$ Esse conceito será trabalhado posteriormente.

${ }^{206}$ RAWLS, 1996. Op.cit.

${ }^{207}$ A concepção de pessoa de Rawls sofreu duras e veementes críticas. As principais foram desenvolvidas por Michael Sandel e Charles Taylor. SANDEL, Michael. Liberalism and the limits of justice. Cambridge, Cambridge University Press, 1982. TAYLOR, Charles. Atomism. IN: ANIVERI, S.; DE-SHALIT, A. Communitarianism and Individualism. Oxford, Oxford University Press, 1992.

208 “Capacidade de entender a concepção pública de justiça que caracteriza os termos equitativos da cooperação social, de aplicá-la e de agir de acordo com ela" (RAWLS, 2000, p.62) 209 "capacidade de formar, revisar e procurar concretizar racionalmente uma concepção de vantagem racional pessoal, ou bem" (RAWLS, 2000, p.62).
} 
Dizer que um cidadão é livre por possuir a faculdade moral de ter uma concepção do bem não implica que não exista a possibilidade de existir uma identidade pública de pessoa. Assim, os cidadãos podem ao longo de sua vida alterar sua concepção de bem sem modificar sua identidade pública. O que está em jogo aqui é a possibilidade de existirem diversas concepções de bem, que podem ser alteradas com o passar do tempo, e uma esfera pública de identidade. Assim, posso assumir compromisso e ter ligações na vida não pública (identidade moral) distintas de que os outros indivíduos, mas isso não prejudica ou não trariam prejuízos à vida pública. Contudo, é necessário que os cidadãos ajustem e reconciliem as duas dimensões de sua identidade moral. Nesses termos, a identidade institucional e moral podem coincidir.

Os cidadãos têm o direito de fazer reivindicações para promover suas concepções do bem. Essas reivindicações fundadas nos deveres e obrigações de suas próprias concepções de bem e sua doutrina moral são autoautenticadoras. Aqui está sendo pressupostas concepções de bem que não são incompatíveis com a concepção pública de justiça.

Os cidadãos são livres na medida em que podem assumir responsabilidades por seus objetivos. Isso permite que eles avaliem suas próprias reivindicações. Assim, numa sociedade em que a estrutura básica é justa e as pessoas equitativamente compartilham os bens primários, os cidadãos podem ajustar seus objetivos e aspirações ao que é razoável, podem ou são capazes de restringir suas demandas àquelas autorizadas ou que estão de acordo com os princípios de justiça.

A concepção política de pessoa ancorada na ideia de identidade pública não assume ou não pretende assumir compromisso com nenhuma concepção metafísica, epistemológica ou moral abrangente de pessoa. Contudo, como conceito extraído da cultura política pública das sociedades democráticas exprime a diversidade das concepções morais, filosóficas e religiosas possíveis pelo pluralismo razoável. Não parece ser um conceito completamente desraízado ${ }^{210}$. Embora seja um conceito normativo assume valores construídos e presentes, social e historicamente, em sociedades democráticas.

\subsection{Consenso Sobreposto}

O consenso sobreposto é uma das principais ideias apresentadas por Rawls em LP. Ela é apresentada como a alternativa para se pensar a unidade social e estabilidade em sociedades democráticas bem ordenadas marcadas pelo pluralismo razoável. Com ela é possível se conceber um consenso em que as doutrinas razoáveis possam endossar uma concepção política a partir de seu próprio ponto de vista. ${ }^{211}$

\footnotetext{
${ }^{210}$ Sendo assim, parece não proceder a crítica feita por Sandel. Todavia, reconhece-se que o ponto deveria ser melhor discutido.

${ }^{211}$ Rawls, 1996. Op. Cit.p.30.
} 
Diferentemente das outras concepções de justiça, o liberalismo político admite a ideia de que existe uma diversidade de doutrinas abrangentes e razoáveis que mesmo conflitando entre si, por apresentarem concepções de bem diferentes, aceitam a possibilidade de compartilhar ou endossar uma concepção política de justiça. Em contraposição à tradição, ele sustenta que não é possível que doutrinas abrangentes possam fundar uma concepção política para um regime constitucional.

A impossibilidade de uma doutrina abrangente ser a base de uma concepção política radica no fato de que nenhuma delas, por querer impor uma única concepção do bem, atende a pluralidade e complexidade das sociedades modernas. Dado o pluralismo razoável, produto da razão prática no decorrer do tempo sob instituições livres e duradouras, é necessário uma concepção de justiça que seja apenas política e respeite tal fato.

O liberalismo político apresenta a ideia de consenso sobreposto para resolver esta questão. Dois pontos importantes pressupostos devem ser destacados: a) trata-se de um consenso entre doutrinas abrangentes razoáveis e b) que a concepção pública política que dele decorrerá seja independente de doutrinas abrangentes de qualquer tipo. ${ }^{212}$

O consenso sobreposto é resultado de um procedimento que envolve dois passos: o do consenso constitucional e do consenso sobreposto propriamente dito. $\mathrm{O}$ consenso constitucional não é profundo, nem amplo. Ele implica apenas na aceitação de alguns princípios de justiça política. Estes serão assegurados na constituição que estabelece procedimentos eleitorais democráticos que moderam a rivalidade política presente na sociedade. Nesse sentido ele é apenas procedimental, uma vez que estabelece os procedimentos políticos do governo democrático.

O consenso constitucional pode ser criado quando por razões históricas certos princípios liberais de justiça são incorporados às instituições existentes e são aceitos como modus vivendi. Há uma aceitação inicial e com o passar dos tempos tais princípios passa a ser endossados pelos cidadãos. Tal endosso pode ocorrer por razões cognitivas ou práticas. Cognitivas, porque nem sempre os cidadãos percebem a conexão entre os princípios políticos e sua concepção de bem, facilitando assim a compatibilização entre ambos. Práticas, os cidadãos avaliam os benefícios que mencionados princípios trazem para si e para a sociedade e os apoiam. ${ }^{213}$

O consenso constitucional ocorrerá caso exista estabilidade. Para que isso aconteça, três requisitos são necessários. Primeiro, os princípios liberais devem satisfazer o conteúdo de certas liberdades e direitos políticos fundamentais, dando a eles prioridade especial; segundo, um determinado tipo de razão pública é exigido na aplicação desses e por fim, o encorajamento de virtudes cooperativas pela incorporação dos princípios nas instituições básica e pela razão pública gestada na aplicação deles.

\footnotetext{
${ }^{212}$ RAWLS, 1996. Op. Cit.p.40.

${ }^{213}$ RAWLS, 1996. Op. Cit.p.41
} 
Sendo esses três requisitos atendidos, tem-se que as doutrinas professadas pelos cidadãos se não são, tornam-se razoáveis, e o consenso constitucional efetivase. Contudo, o consenso constitucional não é consenso sobreposto, mas é necessário para que este ocorra.

Como um consenso constitucional torna-se um consenso sobreposto? O consenso constitucional tem como objeto certos princípios de liberdades, direitos políticos fundamentais e procedimentos democráticos, mas não atinge a estrutura básica da sociedade. Por outro lado, o consenso sobreposto é um acordo profundo sobre os princípios e ideais políticos (profundidade) que tem por base e foco uma concepção política de justiça (especificidade) que procura abarcar a estrutura básica da sociedade (extensão). Como a passagem do primeiro para o segundo é possível? Como um consenso sobre os procedimentos políticos de governos democráticos pode transformar-se ou ser uma etapa que antecede o acordo sobre pontos mais fundamentais e substanciais?

Rawls ${ }^{214}$ sustenta que existem forças que levam um consenso constitucional para um consenso sobreposto. As divide de acordo com o critério da profundidade, da extensão e da especificidade. Quanto ao critério da profundidade há duas forças: a primeira diz respeito ao fato de que os grupos políticos, após o consenso constitucional, precisam participar do fórum público de discussões e dirigir-se àqueles que não têm a mesma doutrina abrangente. A segunda refere-se às autoridades responsáveis pela revisão judicial. Elas precisam desenvolver uma concepção política de justiça que será a base para a interpretação da constituição e para a solução dos casos importantes.

Quanto à extensão o consenso constitucional é muito restrito. É necessária uma legislação que garanta as liberdades de consciência e pensamento, que assegure as liberdade de associação e movimento e medidas que salvaguardem que as necessidades básicas de todos os cidadãos sejam satisfeitas, possibilitando a eles a participação na vida política e social. De acordo com Rawls ${ }^{215}$, o ponto constitucional mais relevante é o de que "abaixo de certo nível de bem-estar material e social, e de treinamento e educação, as pessoas simplesmente não podem participar da sociedade como cidadãos, e muito menos como cidadãos iguais". Pode - se dizer que o consenso sobreposto também se estende sobre às condições materiais e culturais da vida dos cidadãos. Contudo, cabe ressaltar que ele não ultrapassa a esfera do político.

Em relação à especificidade o consenso sobreposto somente pode ser alcançado se as concepções liberais, e mais precisamente, a justiça como equidade, que dele possam tomar parte tenham como ponto de partida as ideias políticas fundamentais de uma cultura política pública democrática e os interesses políticos e

\footnotetext{
${ }^{214}$ RAWLS, 1996. Op. Cit..116.

${ }^{215}$ RAWLS, 1996. Op. Cit.. p 116 : “[...] essential here is rather that below a certain level of material and social well-being, and of training and education, people simply cannot take part in society as citizens, much less as equal citizens".
} 
econômicos que encorajam não sejam profundamente divergentes.

Essas condições ou forças tornam possível o consenso sobreposto. Ele é resultado de um processo que paulatimente toma corpo a partir da aceitação inicial de uma concepção liberal de justiça. Contudo, Rawls ${ }^{216}$ acredita que o consenso sobreposto pode estar aberto à algumas objeções.

A primeira delas relaciona-se a ideia de que o consenso sobreposto seja apenas um modus vivendi. Esse é uma espécie de acordo provisório que partes em litígio aceitam mas que em determinadas circunstâncias podem rompê-lo para realizar seus próprios interesses ou objetivos. Ele ocorre quando há um consenso social fundado em interesses pessoais ou na negociação política.

Como se destacou acima, o consenso constitucional, etapa necessária para que ocorra o consenso sobreposto, pressupõem um modus vivendi. Contudo, o consenso sobreposto não é modus vivendi. De acordo com Rawls ${ }^{217}$, há três elementos que destacam a diferença daquele para este: a natureza do objeto, o tipo de razões que o justificam e a estabilidade. O objeto do consenso, a concepção política de justiça, é uma concepção moral e o tipo de razões que são apresentadas para endossar tal concepção também é moral. Aqueles que endossam a concepção política de justiça o fazem a partir de sua própria doutrina abrangente.

Esses dois elementos estão ligados a estabilidade. As diversas visões que dão sustentação a concepção política de justiça não a deixaram de endossá-las, caso uma delas se torne dominante. Embora haja alteração na distribuição de poder político não haveria alteração na concepção política de justiça. É a estabilidade que efetivamente permite afirmar que o consenso sobreposto não é um modus vivendi. Contudo, cabe ressaltar que esse é precário e contingente, enquanto aquele pretende ser profundo e necessário.

A segunda objeção está relacionada à tese de que uma concepção política de justiça implicaria indiferença ou ceticismo em relação a ela poder ser verdadeira. $\mathrm{O}$ argumento de Rawls preocupa-se em mostrar que uma concepção política de justiça pode ser considerada verdadeira ou razoável, uma vez que aqueles que a apoiam o fazem a partir da sua própria visão doutrinária abrangente. Aqui parece existir a pressuposição de que as concepções que as pessoas professam, pelo menos de acordo com a avaliação delas, são entendidas como verdadeiras. Destarte, embora o endosso seja fundado na própria visão abrangente, existe a crença de que a concepção política seja verdadeira ou razoável. Em termos de crença, a veracidade ou a razoabilidade desta são critérios para o endosso. Tende-se a não aceitar e não endossar concepções, independente da sua natureza, que não atendam os critérios mencionados.

Outro aspecto do argumento rawlsiano é saber se tal entendimento não pressupõe indiferença ou ceticismo. A concepção política de justiça trata das

\footnotetext{
${ }^{216}$ RAWLS, 1996. Op. Cit..117

${ }^{217}$ RAWLS, 1996. Op. Cit. 117.
} 
questões fundamentais e, por isso, determinadas questões controversas por razões morais, filosóficas ou religiosas, não figuram ou precisam ser retiradas da agenda política. A retirada de certas questões da agenda política funda-se no critério da razoabilidade. Como destaca Rawls, se uma concepção de justiça assegura as liberdades políticas e civis, a escravidão e a servidão precisam ser excluídas da agenda política. Essa exclusão precisa ser justificada publicamente por argumentos e razões. Entretanto, não há como excluir todas as questões controvertidas da agenda política. A opção por não absolutizar a posição é tornar possível a realização do consenso sobreposto.

Uma terceira objeção que pode ser feita é de que uma concepção política de justiça precisa ser geral e abrangente. Caso, a concepção não tenha essas características não há como resolver os profundos conflitos de justiça fundados em bases conceituais e filosóficos. Desse modo, a solução será encontrada quando o nível de reflexão filosófica for geral e abrangente. Essa objeção não cabe dado o fato de a concepção política de justiça é pluralista e não unificada. Ela não pretende dar respostas a todas as questões de justiça e algumas delas ficarão sem respostas. Ela é apenas "guia para orientar a deliberação e a reflexão que nos ajudam a chegar a um acordo político, pelo menos sobre os elementos constitucionais essenciais e sobre as questões básicas da justiça". ${ }^{218}$

A quarta objeção discutida por Rawls é aquela de que não há forças políticas, sociais ou psicológicas suficientes para gerar e estabilizar o consenso sobreposto senso ele portanto utópico. A pouco acima recuperei o argumento destacado por Rawls. Mencionando brevemente chamo atenção para o procedimento de passagem do consenso constitucional para o consenso sobreposto e as forças que têm papel relevante nessa trajetória. Rawls de forma sintética recapitula seu argumento:

Esbocei [...] a forma pela qual uma aquiescência inicial a uma concepção liberal de justiça enquanto simples modus vivendi poderia mudar com o passar do tempo, transformando-se primeiro num consenso constitucional e de depois num consenso sobreposto. Nesse processo, pressupus que as doutrinas abrangentes da maioria das pessoas não são abrangentes, o que admite um espaço para o desenvolvimento de uma adesão para o desenvolvimento de uma adesão independente à concepção que ajuda criar um consenso. Essa adesão independente, por sua vez, leva as pessoas a agirem com intenção evidente de acordo com os arranjos constitucionais, desde que tenham uma garantia razoável de que as outras farão o mesmo. Gradualmente, à medida que o sucesso da cooperação política se mantém, os cidadãos ganham uma confiança cada vez maior uns nos outros. ${ }^{219}$

\footnotetext{
${ }^{218}$ RAWLS, 1996. Op.cit., p. 156.

${ }^{219}$ RAWLS, 1996. Op.cit., p. 168.
} 
Rawls pretende rechaçar esta objeção com dois argumentos: primeiro, as doutrinas não abrangentes admitem um espaço para que as pessoas possam aderir a uma concepção pública de justiça, concepção que cria o consenso e b) a "adesão independente" é a força motivacional que conduz as pessoas a agirem de acordo com os arranjos. ${ }^{220}$

A geração e a estabilidade do consenso sobreposto têm como fundamento ideias presentes na cultura pública de fundo que são aceitas e incorporadas ao modo de ser e comportar-se doa cidadãos e as instituições criam um espaço político permeado de valores dessa mesma natureza que são endossados por visões abrangentes distintas. Claro deve ficar nesse contexto a importância da ideia de razão pública. Esta será analisada no próximo tópico.

\subsection{A IDEIA DE RAZÃo PÚBlica}

Neste tópico serão discutidos aspectos relevantes da ideia de razão públi$\mathrm{ca}^{221}$. Inicialmente a categoria será definida e contrastada com a noção de razão não pública. Na sequência, serão expostas as questões, o conteúdo e os fóruns nos quais a razão pública se apresenta e se efetiva.

Em LP a ideia de razão pública ocupa a posição central que a noção de posição original ocupa em TJ. Para dar conta da principal questão do Liberalismo político, a saber: como é possível existir, ao longo do tempo, uma sociedade justa e estável de cidadãos livre e iguais, mas que permanecem profundamente divididos por doutrinas religiosas, filosóficas e morais razoáveis, Rawls concebe o consenso sobreposto entre doutrinas abrangentes como a maneira para que seja possível uma base política comum. Contudo, para que o consenso sobreposto ocorra é necessário a utilização da razão pública. A razão pública é a razão dos cidadãos de uma sociedade democrática enquanto compartilham a situação de cidadania e seu objeto é o bem público em uma concepção pública de justiça que tem uma base pública de justificação. ${ }^{222}$

Com base nessa definição, fica claro a relação que a ideia de razão pública

\footnotetext{
${ }^{220}$ Aceita-se que a resposta rawlsiana às objeções são adequadas e sólidas. Deste modo, considera-se o consenso sobreposto como o processo que permite fixar as regras públicas de justificação e que pode conduzir as pessoas a procurar acordos institucionais. Contudo, isso não explica o porque alguém deve está obrigado a agir de acordo com aquilo que foi objeto de consenso.

${ }^{221}$ A ideia de razão pública desenvolvida por Rawls é uma das principais contribuições já dadas por uma autor para a teoria democracia. De acordo com Bohman e Regh, ele formulou "os detalhes filosóficos da justificação fundada na deliberação e razão pública".

222 "Public reason is characteristic of a democratic people: it is the reason of its citizens,of those sharing the status of equal citizens. The subject of their reason is the good of the public: what the political conception of justice requires of society's basic structure of institutions, and the purposes and ends they are to serve". RAWLS, 1996. Op.cit., p. 214.
} 
tem com outras duas noções: a de justificação pública e consenso. De acordo com Rawls $^{223}$ a razão é pública em três sentidos: (i) é a razão do público, isto é, a razão dos cidadãos enquanto compartilham de uma situação de igual cidadania; (ii) seu objeto é o bem público e as questões de justiça fundamentais;(iii) a natureza e o conceito são públicos, determinados pelos princípios expressos pela concepção de justiça política.

A fim de esclarecer melhor o que Rawls entende por razão pública elabora-se um contraste com a noção de razão não-pública. A principal diferença é a de existem várias razões não públicas e apenas uma razão pública. As razões não-públicas são aquelas expressas por igrejas, universidades, sociedades científicas e grupos profissionais. São razões sociais e compreendem as diversas razões da sociedade civil e fazem parte da "cultura de fundo" em contraste com a cultura política pública. ${ }^{224}$

Especificando melhor a sua definição de razão pública, Rawls ${ }^{225}$ afirma que ela "é a razão de cidadãos iguais que, enquanto corpo coletivo, exercem um poder político final e coercitivo uns sobre os outros ao promulgar leis e emendar sua constituição" . Essa definição remete ao fato de que a razão pública deve ser utilizada para tratar de algumas questões políticas. Ela deve ser usada para tratar de qualquer questão política? Não, apenas daquelas que envolvem os elementos constitucionais essenciais e as questões de justiça básica. São exemplos de questões tratadas pela razão pública: "quem tem direito ao voto, que religiões devem ser toleradas, a quem se deve garantir igualdade equitativa de oportunidades, ou ter propriedades" Para resolver essas questões valores políticos devem ser considerados. Contudo, há questões políticas que o apelo aos valores da razão pública não são suficientes.

As questões e os valores abordadas pela razão pública e por elas assegurados são de natureza política. Daí decorre a necessidade das questões e valores políticos serem tratados num fórum específico, o fórum público. Nesse, o ideal de razão pública se efetiva na argumentação política dos cidadãos, dos membros dos partidos e candidatos em campanha e grupos que os apoiam. Ela também aparece quando os cidadãos devem votar nas eleições quando os elementos constitucionais e as questões de justiça básica estão em jogo. ${ }^{226}$

Além do fórum público onde os cidadãos argumentam politicamente há os fóruns oficiais. Estes fóruns referem-se aos argumentos públicos proferidos pelas autoridades legislativas, executivas e judiciárias. Afirma Rawls:

${ }^{223}$ RAWLS, 1996. Op. Cit.

${ }^{224}$ RAWLS, 1996. Op. Cit.

${ }^{225}$ RAWLS, 1996. Op. Cit., p.214. "[...]public reason is the reason of equal citizens who, as a collective body, exercise final political and coercive Power over one another in enacting laws and in amending their constitution".

226 “Portanto, o ideal de razão pública não só governa o discurso público das eleições , quando as questões fundamentais estão em jogo, como também a forma pela qual os cidadãos devem escolher no que votar a respeito dessas questões”. RAWLS, 1996. Op. Cit.., 215. 
Esse ideal aplica-se aos fóruns oficiais e, por isso, aos legisladores, quando falam no recito do parlamento, e ao executivo, em seus atos e pronunciamentos públicos. Aplica-se também, de forma especial, ao judiciário e, sobretudo, ao supremo tribunal numa democracia constitucional com controle de constitucionalidade das leis. ${ }^{227}$

O fórum oficial é uma modalidade do fórum público. Contudo, ele tem uma especificidade, é constituído por pessoas investidas de autoridade e que ocupam posições políticas relevantes e privilegiadas do ponto de vista discursivo.

Um detalhe importante na passagem acima mencionada é o destaque que Rawls dá a um dos fóruns especiais, o do judiciário. A peculiaridade desse fórum é que nele os juízes precisam justificar suas decisões com base na constituição e nos precedentes. Assim, como isso não ocorre nos outros dois fóruns, no legislativo e no executivo, "o papel especial do tribunal faz dele um caso exemplar de razão pública". 228

Um breve comentário sobre esse ponto. De acordo com Rawls, num regime constitucional com revisão judicial a razão do supremo tribunal é manifestação mais elevada da razão pública. Duas teses são avançadas por Rawls: i) a razão pública é apropriada para ser a razão do tribunal a medida que cumpre seu papel de intérprete judicial supremo e ii) o supremo tribunal é o componente do Estado que exprime exemplarmente a razão pública.

Assim, o Supremo Tribunal Federal229, no exercício de sua função de interprete, é o dispositivo institucional adequado para proteger a lei mais alta, a constituição. Ao exercer este papel o tribunal pretende evitar que as leis sejam distorcidas por maiorias legislativas transitórias ou por interesses articulados de alguns membros do parlamento ou que ocupam postos políticos relevantes. No exercício desta função, a razão pública realiza o papel atribuída por Rawls: articuladora do ideal político que uma constituição democrática assegura e exprime.

O papel atribuído ao Supremo Tribunal está de acordo com a ideia de uma democracia constitucional dualista. Em uma democracia dualista ${ }^{230}$, o poder cons-

227 "It apliplies in officil fóruns and so to legislators when they speak on the floor of parliamnet, and to the executive in its public acts and pronouncements. It applies also in special way to the judiary and above all to a supreme court in a constitutional democracy with judicial review". RAWLS, 1996. Op. Cit.., p.215.

228 "[...] the court's special role makes it exeplar of public reason". RAWLS, 1996. Op. Cit., p. 216.

${ }^{229}$ Denominação utilizada no Brasil

${ }^{230}$ Uma democracia constitucional apresenta ou salvaguarda os cinco princípios do constitucionalismo: a) distinção entre o poder constituinte do povo de estabelecer um novo regime e o poder ordinário das autoridades do governo e do eleitorado; b) distinção entre a lei mais alta (constituição) e a lei comum; c) 
tituinte difere do poder ordinário e a constituição (lei mais alta do povo) das leis ordinárias dos órgãos legislativos.

Efetivamente, o papel do tribunal é dar existência adequada e contínua à razão pública. O que isso implica? De acordo com Rawls:

[...] a razão pública é única razão que o tribunal exerce. Ela é o único ramo do Estado que é diretamente e visivelmente a criação dessa razão, e dela somente. Os cidadãos e os legisladores podem votar de acordo com suas visões abrangentes quando os elementos constitucionais essenciais e a justiça básica não estiverem em jogo; não precisam justificar, por meio da razão pública, porque votam dessa ou daquela maneira, ou dar consistência a suas razões e articulá-las numa visão constitucional coerente, que abranja todas as suas decisões. O papel dos juízes e fazer exatamente isso e, ao fazê-lo, não têm nenhuma outra razão e nem quaisquer outros valores além daqueles de índole política. À parte isso, devem agir de acordo com o que pensam estar sendo requerido pelos casos, práticas, tradições constitucionais e pelos textos históricos constitucionalmente significativos. ${ }^{231}$

Sendo o Supremo Tribunal o guardião da constituição, ele obrigatoriamente deve preservar os elementos constitucionais essenciais e a justiça básica. Desse modo, a sua razão ou razões deve ser de natureza exclusivamente política.

Nesse contexto é função dos juízes exprimirem, em suas opiniões refletidas, as melhores interpretações que puderem compor da constituição. De acordo com Rawls, a melhor interpretação é aquela que articula adequadamente o material constitucional existente com base numa concepção pública de justiça ou com uma de suas alternativas razoáveis. Portanto, eles apelam para os valores políticos presentes nessa concepção. Fazem eles uma interpretação adequada da cara tradição constitu-

a constituição democrática fundada em princípios exprime o ideal político de organização de um povo; d) por meio de uma constituição democraticamente ratificada e que apresenta uma carta de direitos, o conjunto de cidadãos emoldura elementos constitucionais básicos como, por exemplo: os direitos e liberdades fundamentais e iguais e e) o poder supremo de um governo democrático cabe aos três poderes, que assumindo cada um a sua função justifica-se e responde ao povo. ". RAWLS, 1996. Op. Cit.

231 " [...] public reason is the sole reason the court exercises. It is the only branch of government that is visibly on its face the creature of that reason and of that reason alone. Citizens and legislators may properly vote their more comprehensives views when constitutional essentials and basic justice are not at stake; they need not justify by public reason why they vote as they do or make their grounds consistent and fit the mint a coherent constitutional view over the whole range of their decisions. The role of the justices is to do precisely that and in doing they have no other reason and no other values than political. Beyond that they are to go by what they think the constitutional cases, practices, and traditions, and constitutionally significant historical texts require". RAWLS, 1996. Op. Cit., p.235. 
cional à luz dos valores políticos de uma concepção política de justiça. Procedendo dessa forma, o tribunal no exercício da razão pública sugere a publicidade da razão e o papel educativo da razão pública.

O Supremo Tribunal enquanto aquele que exprime a razão pública, além dos aspectos já mencionados, dá força e vitalidade a ela no fórum público. Ele cumpre essa função no momento em que julga de forma razoável as questões políticas fundamentais.

\section{O papel da razão pública no Supremo Tribunal Federal}

Retoma-se a linha de raciocino, apresentando-se, novamente, alguns pressupostos da teoria rawlsiana sobre os quais pode-se inferir a função da razão pública nas deliberações do STF, a saber:

Primeiro, na justiça como equidade as instituições sociais têm o papel de em definindo os princípios de justiça promovê-los. Essas instituições (políticas, sociais e econômicas) devem, com base em tal justiça, desenvolver suas atividades de forma cooperativa privilegiando o caráter deliberativo em decisões políticas fundamentais.

Segundo, o pluralismo das sociedades modernas valida a necessidade de se estabelecer para temas morais controvertidos uma concepção pública de justiça adstrita à princípios e valores políticos.

Terceiro, as instituições de um regime democrático têm o compromisso de atuarem em conformidade com a ideia de razão pública uma vez que dela emana o conteúdo dos princípios de justiça a serem aplicados em suas ações políticas.

Com base nessas três constatações, expostas como pressupostas na teoria de John Rawls, defende-se que, o STF, como instituição constituinte da estrutura básica de uma sociedade democrática, deve atuar a partir de critérios deliberativos rigorosamente estabelecidos, ou seja, orientado pela ideia de razão pública como forma de preservar os princípios de justiça de influências ideológico-partidárias.

Rawls preconiza que em regimes constitucionais com controle de constitucionalidade a expressão máxima da razão pública é a razão do Supremo Tribunal. O filósofo pretende com essa distinção lançar luz sobre o importante encargo conferido a esse Poder, qual seja o de manter a coerência entre as prescrições normativas e a Constituição ao conformar o ordenamento jurídico aos princípios e valores da justiça como equidade mantendo o espírito da lei maior, de certa forma, imune às distorções de maiorias legislativas transitórias.

A qualidade de exegeta supremo da Constituição atribuída ao Supremo Tribunal, segundo Rawls, remonta a distinção feita por John Locke entre o poder constituinte e o poder constituído. O filósofo defende que nesse modelo a supremacia parlamentar é rejeitada. Isso quer dizer que, quando o Supremo Tribunal ao interpretar a lei constitucional, desempenhar efetivamente o ideal da razão pública, 
ele não será antidemocrático.

Mas, por que o Supremo Tribunal ocupa esse lugar de relevo na ideia de razão pública de John Rawls? O filósofo americano responde informando que tal destaque decorre da obrigatoriedade dos ministros em justificando suas decisões invocarem em suas reflexões apenas valores políticos que julgam serem parte de um entendimento mais razoável de uma concepção política de justiça e de razão pública. Do dever de preservar os elementos constitucionais essenciais e de justiça básica associada à maneira pela qual a Corte pondera suas deliberações é que a torna, segundo Rawls, o único ramo do Estado no qual se pode visivelmente perceber a criação da razão pública.

Cumpre frisar que, o exercício da razão pública nessa esfera não é conjecturado de forma intemerata pelo filósofo. O que Rawls defende é tão somente um procedimento apropriado de interpretação e defesa da Constituição, e não o consenso integral entre os julgadores.

E qual é a função desse mencionado órgão, nesse cenário? Dar à razão pública, por meio de interpretações constitucionais razoáveis, uma existência apropriada e consistente com princípios de justiça de um Estado democrático de direito.

Ao adotar valores políticos de justiça e de razão pública em suas deliberações o Supremo Tribunal desponta como um grande colaborador na construção de uma democracia constitucional, que orientada por uma concepção política de justiça, fortalece o cumprimento das essências constitucionais. Quando esse órgão cumpre como seu papel ele institui, enquanto paradigma da razão pública, uma noção de justiça que inclina os cidadãos no cumprimento de seus deveres de civilidade (RAWLS, 2000, p. 303).

Por conta das limitações teóricas do presente estudo, evitou-se abordar as críticas opostas à teoria rawlsiana. Contudo, à guisa de desfecho reproduz-se uma das objeções à ideia de razão pública que argumenta que tal ideia, enquanto procedimento de justificação pública, na prática é pouco determinante para apontar as decisões políticas mais razoável no caso concreto.

Defende-se, todavia, em face da oposição feita à ideia de razão pública, que uma interpretação criteriosa da formulação rawlsiana de razão pública coloca em evidencia elementos considerados essenciais para uma deliberação democráti$\mathrm{ca}^{232}$.

\section{Conclusão}

As decisões do Supremo Tribunal Federal representam, muitas vezes, um alto impacto político e social, na vida da população brasileira, por tal motivo o uso

${ }^{232}$ Os cidadãos (pessoas livres e iguais) submetem suas decisões políticas a um critério de legitimação racional caracterizada pela possibilidade de reconhecimento por todos os afetados a partir de um juízo público. 
da razão pública como exigência deliberativa se mostra apropriado para a promoção e defesa dos princípios de justiça coerentes com um Estado democrático de direito. Ela tem o papel de formular uma moldura a partir da qual questões políticas fundamentais passam a ser analisadas.

Nesse cenário, a razão pública desponta como sendo o campo de argumentação que melhor representa os compromissos culturais compartilhados, pois ao oferecer uma visão de justiça, cujos princípios assentam no consenso dos cidadãos, ela se torna mais razoável e adequada para guiar as deliberações políticas na esfera jurisdicional. Ela sinaliza quais são ou, quais deveria ser o substrato argumentativo quando estiver em jogo questões políticas fundamentais criando um modelo de argumentação pública que ao prestigia a capacidade racional dos cidadãos na criação de uma nova estrutura social.

Assim, o STF, por conta de suas competências e configuração, tem a função precípua de proteger a Constituição de ações temerárias de maiorias transitórias, bem como proporcionar às pessoas e instituições, por meio de seus exemplos, uma educação no que se refere a questões políticas fundamentais contribuindo na construção dos arranjos institucionais futuros.

Por fim, assume-se que, um Tribunal cujo exercício jurisdicional pauta-se na ideia de razão pública contribui com o Estado democrático de direito nos seguintes termos: a) assegura a legitimidade das instituições políticas e das leis e, b) pavimenta o caminho sobre o qual outras pessoas ao segui-lo serão capazes, ao final, de reconhecerem os princípios de justiça adequados para regularem suas vidas políticas, evitando dessa forma grande parte das violações de liberdade, igualdade ocorridas em todos os tempos.

\section{REFERÊNCIAS}

BOHMAN, James; REGH, Willian. Deliberative democracy. Cambrigde/London: The MIT Press, 1997.

GAUS, Gerald. The turn to Political Liberalism. Disponível em: http://www.gaus. biz/PoliticalLiberalism.pdf . Acessado: 21.08.14.

RAWLS, John. A ideia de Razão Pública Revisitada. In: WERLE, Denilson Luis; MELO, Rúrion Soares (Orgs.). Democracia deliberativa. São Paulo: Singular; Esfera Pública, 2007.

. . A Theory of Justice. Cambridge: Harvard University Press, 1999. . Political Liberalism. New York: Columbia University Press, 1996.

SANDEL, Michael. Liberalism and the limits of justice. Cambridge, Cambridge University Press, 1982. 
TAYLOR, Charles. Atomism. IN: ANIVERI, S.; DE-SHALIT, A. Communitarianism and Individualism. Oxford, Oxford University Press, 1992.

WEITHMAN, Paul. Why Political Liberalism. On John Rawls's Political Turn. New York: Oxford University Press, 2011.

WERLE, Denilson Luis. Justiça e Democracia: Ensaios sobre John Rawls e Jürgen Habermas. São Paulo: Singular; Esfera Pública, 2008. 